\title{
Study to Assess the Risk of Transmission of Microbial Organisms and their Resistance Pattern on Dresses and Stethoscopes of Health Care Workers
}

\author{
E. Nivedhitha ${ }^{1}$, M. Duraivel ${ }^{2 *}$ (D) K.K. Kayalvili ${ }^{(D)}$ and S. Arul Selvan ${ }^{4}$ \\ ${ }^{1}$ Department of Microbiology, SRM Medical College Hospital \& Research Centre, Faculty of Medicine, SRM \\ Institute of Science and Technology, SRM Nagar, Kattankulathur, 603203, Kanchipuram, Chennai, \\ Tamilnadu, India. \\ ${ }^{2}$ Department of Pharmacology, Chettinad Hospital \& Research Institute, Chettinad Academy of Research and \\ Education, Kelambakkam, 603103, Chengalpattu, Tamilnadu, India. \\ ${ }^{3}$ Orbito Asia Diagnostics, St. Thomas Mount, Chennai, Tamilnadu, India. \\ ${ }^{4}$ Department of Forensic Medicine, Govt. Mohan Kumaramangalam Medical College, Salem, Tamilnadu, India.
}

\begin{abstract}
The main objective of the study was to find out the contamination of different types of microbial organisms and their resistance pattern on the dresses and stethoscopes of the health care workers in order to evaluate the risk of transmission of microbial organisms and its consequences on safety of the patient and control of hospital acquired infections (HAIs). Swabs were taken from the dresses of 100 different healthcare workers from 4 different areas namely collar, pocket, sleeves and sides and 100 stethoscopes (diaphragm) were tested for bacteriological analysis using standard techniques. Then each health care worker were given a structured questionnaire and requested to fill the form which includes his or her speciality/unit, cadre, practice of hand hygiene, white-coat or uniform usage (Example: duration of usage, frequency of washing, type of washing etc). The collar and pockets were found to be the most contaminated areas. Gram-positive cocci such as Staphylococcus aureus and Coagulase-negative Staphylococci (CONS) were the important organisms isolated from the dresses and stethoscopes of health care workers followed by Gram-negative bacilli such as Pseudomonas aeruginosa and Klebsiella species. Among the microbial organisms, Staphylococcus aureus and CONS were resistant to the drugs like Co-trimoxazole and Penicillin-G. Organisms isolated from the dresses and stethoscopes of health care workers could be a source of infection to immunocompromised patients. Hence, frequent washing of the dresses and strict disinfectant practices of the stethoscopes will minimize the contamination with microbial organisms and the patient safety is improved in the hospital environment.
\end{abstract}

Keywords: Microbial contamination, dresses of health care workers, stethoscope

*Correspondence: drvlmurugan@gmail.com; +91 9840319516

(Received: February 23, 2021; accepted: June 04, 2021)

Citation: Nivedhitha E, Duraivel M, Kayalvili KK, Selvan SA. Study to Assess the Risk of Transmission of Microbial Organisms and their Resistance Pattern on Dresses and Stethoscopes of Health Care Workers. J Pure Appl Microbiol. 2021;15(3):1150-1155. doi: 10.22207/JPAM.15.3.04

(C) The Author(s) 2021. Open Access. This article is distributed under the terms of the Creative Commons Attribution 4.0 International License which permits unrestricted use, sharing, distribution, and reproduction in any medium, provided you give appropriate credit to the original author(s) and the source, provide a link to the Creative Commons license, and indicate if changes were made. 


\section{INTRODUCTION}

Transmission of infections from one patient to other in the hospital environment remains to be a major concern for the hospitalized patients. ${ }^{1}$ Patients can shed infectious microbial organisms into the healthcare environment and pose a risk of transmission of infection to the other inpatients. Healthcare workers also can transmit infection by virtue of their constant contact with the patients. There has been a growing concern that the dresses of the health-care workers ${ }^{2-3}$ and devices such as stethoscopes ${ }^{4}$ may actually play a vital role in transmitting the pathogenic microorganisms in a hospital setting. This has yet to be studied in developing countries as there is an increasing incidence of Hospital acquired infections (HAIs) and for which there is a dire need to introduce effective patient-safety initiatives to decrease HAl. Hence, this study is planned to identify the occurrence of microbial contamination in the dresses and stethoscopes of health care workers and to emphasize the importance of these microorganisms in control of HAls.

\section{MATERIALS AND METHODS}

A total of 100 health care workers from different specialities or cadres participated in this study. Swabs were taken from dresses of the health care workers in 4 different areas namely collar, pocket, sleeves and sides and also from 100 different stethoscopes (diaphragm), for bacteriological analysis. Sterile, cotton tipped and plain swabs were used for the bacteriological culture. Normal saline was used to wet the swabs and samples were taken by rolling the swabs up and down twice in the preferred areas. Then the swabs were placed in a sterile test tube and transported immediately to the laboratory. They were streaked on to $5 \%$ blood agar and Macconkey agar plate and left for overnight incubation at $37^{\circ} \mathrm{C}$. Next day, culture plates were examined for the presence of bacterial colonies followed by biochemical reactions for the species level identification and antimicrobial sensitivity test were done by standard laboratory methods. After the samples were taken from the health care workers, a brief, structured questionnaire was given to all of them to fill the form which includes his or her speciality/unit, cadre, practice of hand hygiene, white-coat or uniform usage (Example: duration of usage, frequency of washing, type of washing etc).

\section{RESULTS}

The results of the present study are tabulated in table 1-5.

Table 1. Basic variables

\begin{tabular}{|c|c|c|c|c|}
\hline Basic variables & $\mathrm{n}=100$ & $\begin{array}{c}\text { Samples (Collars, } \\
\text { Pockets, Sleeves } \\
\text { and Sides) }\end{array}$ & $\begin{array}{l}\text { Culture } \\
\text { positive }\end{array}$ & $\begin{array}{c}\text { Culture } \\
\text { negative }\end{array}$ \\
\hline \multicolumn{5}{|c|}{ Gender } \\
\hline Male & 59 & 236 & 165 & 71 \\
\hline Female & 41 & 164 & 120 & 44 \\
\hline Total & 100 & 400 & 285 & 115 \\
\hline \multicolumn{5}{|c|}{ Designation } \\
\hline Doctors & 47 & 188 & 157 & 31 \\
\hline Nurses & 31 & 124 & 109 & 15 \\
\hline Paramedical staffs & 22 & 88 & 19 & 69 \\
\hline Total & 100 & 400 & 285 & 115 \\
\hline
\end{tabular}

Most of the health care workers were doctors (47\%) followed by nurses $(31 \%)$ and paramedical staffs $(22 \%)$.

Females $(41 \%)$ were less in number when compared to males $(59 \%)$

Females had higher rate of culture positive $(73 \%)$ than males (70\%) 
Table 2. Isolates from the culture positive samples of the dresses of health care workers

\begin{tabular}{|c|c|c|c|c|c|}
\hline Organisms & $\begin{array}{l}\text { Collar } \\
\mathrm{n}=100\end{array}$ & $\begin{array}{l}\text { Pocket } \\
n=100\end{array}$ & $\begin{array}{c}\text { Side } \\
n=100\end{array}$ & $\begin{array}{l}\text { Sleeve } \\
n=100\end{array}$ & $\begin{array}{l}\text { Total } \\
\mathrm{N}=400\end{array}$ \\
\hline \multicolumn{6}{|c|}{ MONOMICROBIAL } \\
\hline Staphylococcus aureus & 28 & 27 & 26 & 15 & 96 \\
\hline CONS* & 18 & 16 & 12 & 14 & 60 \\
\hline Pseudomonas aeruginosa & 10 & 9 & 13 & 9 & 41 \\
\hline Klebsiella sp. & 2 & 4 & 3 & 3 & 12 \\
\hline Total & 58 & 56 & 54 & 41 & 209 \\
\hline \multicolumn{6}{|c|}{ POLYMICROBIAL } \\
\hline $\begin{array}{l}\text { Staphylococcus aureus + } \\
\text { CONS* + Micrococci }\end{array}$ & 8 & 8 & 8 & 16 & 40 \\
\hline $\begin{array}{l}\text { Staphylococcus aureus + } \\
\text { Pseudomonas aeruginosa }\end{array}$ & 6 & 7 & 4 & 3 & 20 \\
\hline CONS* + diphtheroides & 4 & 2 & 2 & 8 & 16 \\
\hline Total & 18 & 17 & 14 & 27 & 76 \\
\hline Culture Positive & 76 & 73 & 68 & 68 & 285 \\
\hline Culture Negative & 24 & 27 & 32 & 32 & 115 \\
\hline
\end{tabular}

*CONS - Coagulase-Negative Staphylococci

The overall prevalence of microbial contamination in the dresses of health care workers was $71 \%$ ( 285 culture positive samples). Collar and pocket were found to be the most contaminated areas (26\%).

Among 285 culture positive samples, single organism (monomicrobial) was found in 209 samples and 76 samples had multiple organisms (polymicrobial).

In the monomicrobial samples $(n=209)$, Staphylococcus aureus (46\%) was found to be the most common organism isolated. Whereas, in the case of polymicrobial samples $(n=76)$, Staphylococcus aureus, CONS and Micrococci $(53 \%)$ were the most commonly isolated combination.

Table 3. Isolates from the stethoscopes of health care workers $(n=100)$

\begin{tabular}{llll}
\hline Monomicrobial & Total & Polymicrobial & Total \\
\hline Staphylococcus aureus & 31 & Staphylococcus aureus + CONS* + Micrococci & 23 \\
CONS* & 12 & Staphylococcus aureus + Pseudomonas aeruginosa & 6 \\
Pseudomonas aeruginosa & 9 & CONS* Diphtheroides & 3 \\
& 52 & & 32 \\
Culture Positive & 84 & & \\
Culture Negative & 16 & & \\
\hline
\end{tabular}

*CONS - Coagulase-Negative Staphylococci

The overall prevalence of microbial contamination found in the stethoscopes of different Health care workers was found to be $84 \%$ Among the 84 culture positive samples, 52 were monomicrobial and 32 were polymicrobial in nature.

In the monomicrobial samples $(n=52)$, Staphylococcus aureus $(60 \%)$ was found to be the most important organism isolated. Whereas, Staphylococcus aureus, CONS and Micrococci (72\%) were the most common combination of organisms encountered in the polymicrobial samples $(n=32)$.

Overall 3\% of Staphylococcus aureus were found to be MRSA.

\section{DISCUSSION}

The high rates of the microbial contamination in the dresses and stethoscope of health care workers may be related to the fact that patients may continuously shed the infectious microbial organisms into the hospital environment, and the health care workers are in constant contact with these patients. It has also been established that, the microbial organisms can survive for 10 to 98 days on fabrics such as polyesters and cotton which are used to make white coats. ${ }^{5}$ 
Table 4. Antibiotic resistance pattern of the isolates obtained from both the dresses and stethoscopes of healthcare workers

\begin{tabular}{lcccc}
\hline Antibiotics & $\begin{array}{c}\text { Staph. } \\
\text { aureus } \\
\mathrm{n}=216\end{array}$ & $\begin{array}{c}\text { CONS* } \\
\mathrm{n}=154\end{array}$ & $\begin{array}{c}\text { Pseudomonas } \\
\text { aeruginosa } \\
\mathrm{n}=76\end{array}$ & $\begin{array}{c}\text { Klebsiella Sp. } \\
\mathrm{n}=12\end{array}$ \\
\hline Cotrimoxazole & 192 & 120 & $\mathrm{NT}$ & 7 \\
Penicillin G & 168 & 123 & $\mathrm{NT}$ & $\mathrm{NT}$ \\
Gentamicin & 149 & 111 & 30 & 3 \\
Erythromycin & 80 & 51 & $\mathrm{NT}$ & $\mathrm{NT}$ \\
Ciprofloxacin & 86 & 70 & 52 & 10 \\
Cefoxitin & 6 & 0 & $\mathrm{NT}$ & $\mathrm{NT}$ \\
Amikacin & $\mathrm{NT}$ & $\mathrm{NT}$ & 27 & 2 \\
Cefotaxime & $\mathrm{NT}$ & $\mathrm{NT}$ & $\mathrm{NT}$ & 0 \\
Ceftriaxone & $\mathrm{NT}$ & $\mathrm{NT}$ & $\mathrm{NT}$ & 0 \\
Ceftazidime & NT & NT & 0 & NT \\
Piperacillin & NT & NT & 0 & NT \\
\hline
\end{tabular}

*CONS - Coagulase-Negative Staphylococci; NT- Not tested.

Cotrimoxazole and Penicillin G were found to have maximum resistance for Gram-positive cocci such as Staphylococcus aureus and Coagulase-negative Staphylococci (CONS) whereas, Ciprofloxacin have the maximum resistance for the Gram-negative bacilli such as Klebsiella sp and Pseudomonas aeruginosa

Table 5. Questionnaires

1. How often do you wash your coat/ uniform?

$$
n=100
$$

$\begin{array}{ll}\text { a. Daily } & 17 \\ \text { a. Twice a week } & 51 \\ \text { b. Once a week } & 11 \\ \text { c. Once in 15 days } & 13 \\ \text { d. Once a month } & 8\end{array}$

2. Where all do you wear your coat/ uniform?
a. Only in wards

\section{8}
b. Wards and also within campus including canteen and mess 63
c. Inside and outside campus

3. How often do you use sanitizer during working hour?
a. Immediately after handling a patient
31
b. Before handling a patient
16
c. Before and after attending patients
29
d. Never
24

4. How do you wash your uniform/coat?
a. Autoclave
b. Self-washing

5. Do you usually carry articles in your coat/uniform pocket?
a. Yes
b. No

6. Is your coat half sleeve or full sleeve?
a. Half sleeve
92
b. Full sleeve
8

$63 \%$ of the health care workers used their white coats in wards, within campus including canteen and mess.

All the health care workers were found to wash their coats on their own and $51 \%$ of them wash their coats twice a week. Hand hygiene using sanitizers was practiced by $29 \%$ of the health care workers before and after attending patients. 
Since the dresses and stethoscopes of health care workers can transmit the infections from one to another, we have designed this present study in around 100 different health care workers from various specialities or cadres in the hospital. From each individuals, one swab from the stethoscope $(n=100)$ and four swabs from different parts of their dresses such as collar, pocket, sleeves and sides $(n=400)$ were taken for bacteriological analysis.

Among the 100 health care workers, most of them were doctors (47) followed by nurses (31) and paramedical staffs (22). Though females (41\%) were less in number compared to males (59\%), they had higher rate of bacterial contamination (73\%). [Table 1] This finding was similar to the study findings by Muhadi et $\mathrm{al}^{6}$ and contrary to the study findings of Banu et $\mathrm{al}^{7}$ who found out that male worker dresses are more contaminated than females.

Our study result showed, out of 400 samples, 285 samples (71\%) were found to be contaminated with micro-organisms which is much lower compared to the study done by Moravvej et $\mathrm{al}^{8}(94 \%)$ and Uneke \& ljeoma $^{9}(91.3 \%)$.

Collar and pocket of the dresses of health care workers were equally contaminated (26\%) and was slightly more than the contamination on the sides and sleeves of the dresses (24\%). This observation was similar to the study findings of Muhadi et $\mathrm{al}^{6}$ and Banu et $\mathrm{al}^{7}$ who showed that the collar and pockets are the most contaminated areas. [Table 2]

All the health care workers wash their coats on their own and more than $50 \%$ of the hospital workers wash their coats twice a week. The data from washing practices of dresses of health care workers revealed that the microbial organism contamination varied with the duration of the coats in use. This was contrary to the findings of Wong et $\mathrm{al}^{10}$ who showed that the level of bacterial contamination did not vary with the length of time a dress had been in use.

Among the participants $28 \%$ of them used their white coats only in the wards, while $63 \%$ used it both in wards and as well as within campus including canteen/mess and $9 \%$ used both inside and outside the hospital premises. Similar reports were observed in the study done by Muhadi et al ${ }^{6}$.
$76 \%$ of the health care workers claimed to use hand sanitizer before and after attending patients and the microbial contamination were found to be much less when compared with the non-users (24\%). [Table 5]

In this present study, the most common organism isolated from the dresses of the health care workers was found to be Staphylococcus aureus. This was similar to the study findings of Muhadi et $\mathrm{al}^{6}$, Wong et $\mathrm{al}^{10}$ and Treakle et $\mathrm{a}^{11}$ and different from the study findings by Uneke and ijeoma ${ }^{9}$ in which diphtheroids was found to be the most commonly isolated organism. [Table 4]

Among the samples taken from the stethoscope of 100 different health care workers, as many as $84 \%$ of the stethoscope [Table 3] were contaminated with microorganisms which was comparable to the observations from the previous studies done by Youngster et $\mathrm{al}^{12}$, Zuliani et $\mathrm{al}^{13}$ and Wood et al ${ }^{14}$ which showed that $71-100 \%$ of stethoscopes were contaminated by different microorganisms. Among them, Staphylococcus aureus was found to be the most common isolate followed by the Coagulase-negative Staphylococcus (CONS).

The antimicrobial susceptibility pattern of the Gram-positive cocci such as Staphylococcus aureus and Coagulase-negative Staphylococci (CONS) showed that most of the organisms were resistant to the drug Co-trimoxazole and Penicillin. Whereas, Ciprofloxacin was found to have maximum resistance for the Gram-negative bacilli such as Pseudomonas aeruginosa and Klebsiella $s p$. These findings are consistent with the study results shown by Uneke and ljeoma?

Even though most of the organisms isolated in this present study were considered to be non-pathogenic, a considerable fraction of the isolates were pathogenic. Some of the pathogenic organisms like Methicillin Resistant Staphylococcus Aureus (MRSA), Klebsiella sp and Pseudomonas aeruginosa are infectious to the patients who are admitted in the hospital and play a very important role in transmitting the infections from one patient to another. In this study, the percentage of MRSA isolated was $3 \%$ which was significantly lower than the study findings done by Treakle et $\mathrm{a}^{11}$ where it was reported that $18 \%$ of MRSA are found in the dresses of health care workers. 


\section{CONCLUSION}

This hospital based cross-sectional surveillance study revealed that a large proportion of the dresses of health care workers and stethoscope were contaminated with microbial organisms that can result in infections as well as in the spread of resistant strains in the hospital settings. As a result, there is an increasing need to promote a meticulous hand washing and use of hand sanitizers before and after attending the patients. Frequent washing of the uniform and disinfectant of stethoscopes by the health care workers will definitely minimize the cross-contamination with microorganisms and also decrease the chance of hospital acquired infections.

\section{ACKNOWLEDGMENTS}

We owe our heartfelt thanks to the doctors and other health care workers for giving consent to take the samples. We express our deep gratitude for the technical staffs for their assistance in this work.

\section{CONFLICT OF INTEREST}

The authors declare that there is no conflict of interest.

\section{AUTHORS' CONTRIBUTION}

All the authors listed have made a substantial, direct and intellectual contribution to the work, and approved it for publication.

\section{FUNDING}

None.

\section{DATA AVAILABILITY}

All datasets generated or analyzed during this study are included in the manuscript.

\section{ETHICS STATEMENT}

This study involves only the collection of samples from the dresses and stethoscopes of health care workers and the personal information of the participants were not revealed in any part of the study. This article does not contain any studies with human participants or animals performed by any of the authors.

\section{REFERENCES}

1. Collins AS. Preventing Health Care-Associated Infections. In: Hughes RG, ed. Patient Safety and Quality: An Evidence-Based Handbook for Nurses. Rockville (MD): Agency for Healthcare Research and Quality (US); 2008. Chapter 41. https://www.ncbi.nlm. nih.gov/books/NBK2683/

2. Oliveira AM, Silva MD, Garbaccio JL. Clothing of health care professional as potential reservoirs of microorganisms: an integrative review. Texto \& Contexto Enfermagem. 2012;21(3):684-691. doi: 10.1590/ s0104-07072012000300025

3. Lavanya J, Jais M, Rakshit P, Kumar V, Dutta R, Gupta RK. Correlation between Bacterial Pathogens Transfer in Healthcare Workers and Patients: A Study from Paediatric ICU and Nursery of a Tertiary Care Hospital. J Microb Biochem Technol. 2014;6:35-37. doi:10.4172/1948- 5948.1000118

4. Uneke CJ, Ogbonna A, Oyibo PG, Onu CM. Bacterial contamination of stethoscopes used by health workers: public health implications. J Infect Dev Ctries. 2010;4(7):436-441. doi:10.3855/jidc.701

5. Chacko L, Jose S, Isac A, Bhat KG. Survival of nosocomial bacteria on hospital fabrics. Indian J Med Microbiol. 2003;21(4):291. doi: 10.1016/S0255-0857(21)03020-6

6. Muhadi SA, Aznamshah NA, Jahanfar S. A cross sectional study on the microbial contamination of the medical student's white coats. Malays J Microbiol. 2007;3(1):35-38. doi: 10.21161/mjm.00607

7. Banu A, Anand M, Nagi N. White coats as a vehicle for bacterial dissemination. J Clin Diagn Res. 2012;6(8):1381-1384. doi:10.7860/ JCDR/2012/4286.2364

8. Moravvej Z, Fakhar Y, Naderi-Nasab M, Askari E. Study on Bacteria Associated with White Coats of Healthcare Workers in Two Tertiary Hospitals, Mashhad, Iran. J Med Bacteriol. 2013;2(3-4):17-25.

9. Uneke CJ, ljeoma PA. The potential for nosocomial infection transmission by white coats used by physicians in Nigeria: implications for improved patient-safety initiatives. World Health Popul. 2010;11(3):44-54. doi:10.12927/whp.2010.21664

10. Wong D, Nye K, Hollis P. Microbial flora on doctors' white coats. BMJ (Clinical Research ed.). 1991;303(6817):1602-1604. doi: 10.1136/ bmj.303.6817.1602.

11. Treakle AM, Thom KA, Furuno JP, Strauss SM, Harris $A D$, Perencevich EN. Bacterial contamination of health care workers' white coats. Am J Infect Control. 2009;37(2):101-105. doi:10.1016/j.ajic.2008.03.009

12. Youngster I, Berkovitch M, Heyman E, Lazarovitch Z, Goldman M. The stethoscope as a vector of infectious diseases in the paediatric division. Acta Paediatr. 2008;97(9):1253-1255. doi:10.1111/j.16512227.2008.00906.x

13. Zuliani Maluf ME, Maldonado AF, Bercial ME, Pedroso SA. Stethoscope: a friend or an enemy? Sao Paulo Med J. 2002;120(1):13-15. doi: 10.1590/s151631802002000100004

14. Wood MW, Lund RC, Stevenson KB. Bacterial contamination of stethoscopes with antimicrobial diaphragm covers. Am J Infect Control. 2007;35(4):263266. doi: 10.1016/j.ajic.2006.09.004 